\title{
Predation behaviour of Cancer irroratus and Carcinus maenas during conspecific and heterospecific challenges
}

\author{
Marie-Christine Bélair, Gilles Miron* \\ Département de biologie, Université de Moncton, Moncton, Nouveau-Brunswick E1A 3E9, Canada
}

\begin{abstract}
We investigated the predation behaviour of rock crab Cancer irroratus and green crab Carcinus maenas in laboratory experiments in autumn 2006 and spring 2007 during various conspecific and heterospecific challenges. The number of prey eaten by a focal crab during a given challenge was recorded for both crab species using competition treatments (solitary crab, 2 conspecifics or 2 heterospecifics) crossed with 2 different prey densities (4 or 30 mussels) and 3 different temperatures $\left(5,12\right.$ or $\left.20^{\circ} \mathrm{C}\right)$. To validate laboratory results, complementary field experiments were carried out in aquaculture leases in Prince Edward Island, Canada, in 2007, during which crab stomach contents from identical competition treatments were studied and mussel socks were surveyed monthly for crab abundance. In the laboratory, predation rates of both crab species generally increased with temperature and mussel density, and were not affected by the presence of a heterospecific regardless of the season. During autumn 2006, the Temperature $\times$ Mussel density interaction influenced the predation rate of rock crab while only temperature affected the predation rate of green crab. During spring 2007, the predation rate of green crab varied again according to temperature whereas the predation rate of rock crab was affected by the Temperature $\times$ Mussel density $\times$ Competition interaction. In the field, blue mussels Mytilus edulis were the most abundant food item observed in stomach contents. The competition treatments did not affect the stomach contents. Both crab species displayed different abundance patterns and seemed to avoid each other on mussel socks. Overall, our results suggest that the $2 \mathrm{crab}$ species can potentially coexist.
\end{abstract}

KEY WORDS: Predation rate $\cdot$ Cancer irroratus $\cdot$ Carcinus maenas $\cdot$ Introduced species $\cdot$ Competition · Prey density $\cdot$ Temperature $\cdot$ Aquaculture

\section{INTRODUCTION}

Bivalves at culture sites have the potential to attract numerous species (Hidu et al. 1981). Aquaculture gear and cultivated bivalves offer settling surfaces to fouling organisms. Foulers may impede vital functions of bivalves (e.g. valve opening and closing) or compete with them for space and food, and slow their growth (Lodeiros \& Himmelman 2000). The removal of foulers is thus necessary and represents an additional cost to shellfish farmers (Hidu et al. 1981, Ross et al. 2004). In addition, cultivated bivalves and foulers may attract predators to aquaculture areas.
The rock crab Cancer irroratus and the green crab Carcinus maenas are predators commonly found off the east coast of Prince Edward Island (PEI), Canada. Originally from Europe, the invasive green crab appeared in PEI waters in 1997 (Audet et al. 2003). It is a voracious invertebrate predator on invertebrates (Leonard et al. 1999) and considered to be a potential threat to natural (Glude 1955, Floyd \& Williams 2004) or cultivated bivalve populations (Miron et al. 2005). For instance, green crabs contributed to the decline of the native clam species Nutricola confusa and N. tantilla in California, USA (Grosholz et al. 2000), and were strongly associated with the collapse of the softshell 
clam Mya arenaria fishery in northeastern USA during the 1950s (Glude 1955).

Green crabs can also affect indigenous decapods. Densities of the shore crab Hemigrapsus oregonensis, for instance, declined following the invasion of the green crab in California, USA (Grosholz et al. 2000). Experiments showed that green crabs may defend their food against lobsters Homarus americanus of larger size (Williams et al. 2006) and force Dungeness crabs Cancer magister out of their habitat (McDonald et al. 2001). MacDonald et al. (2007) further observed juvenile green crabs to be superior competitors to juvenile blue crabs Callinectes sapidus in food and agonistic laboratory challenges.

Rock crab and green crab have a similar biology. Both are omnivorous and opportunistic foragers (Ropes 1968) and can be found on rocky and sandy substrates (e.g. Scarratt \& Lowe 1972, Grosholz \& Ruiz 1996). They usually feed on the most abundant prey species found within their habitat (Stehlik 1993). Both species have many overlapping resource requirements and may therefore compete for space and food. The green crab is an aggressive competitor and may therefore threaten the native rock crab. Recently, the rock crab status in eastern Canada has given rise to economical concerns (Audet et al. 2003, Williams et al. 2006). Besides being commercially fished, the rock crab is commonly used by PEI shellfish farmers to remove foulers. Farmers temporarily lower their mussel lines to allow rock crabs to climb onto them and dislodge foulers (Hidu et al. 1981) such as the vase, clubbed, or violet tunicates (Ciona intestinalis, Styela clava, or Botrylloides violaceus). Green crabs may impede rock crabs while on mussel socks.

Temperature is an important factor in the life cycle of organisms. It can influence reproduction, fecundity, longevity and growth rate. In PEI waters, temperatures may reach $26^{\circ} \mathrm{C}$ during summer and drop to $-2^{\circ} \mathrm{C}$ in winter (Audet et al. 2008). The green crab is a very active predator between 17 to $24^{\circ} \mathrm{C}$ (Wallace 1973). However, its activity level decreases at $\leq 5^{\circ} \mathrm{C}$ (Beukema 1991). Inversely, the rock crab is sensitive to high temperatures (Vernberg \& Vernberg 1970) and may forage at $3^{\circ} \mathrm{C}$ (Barbeau \& Scheibling 1994).

The interactions between rock crabs and green crabs are poorly documented. If rock crabs are threatened by green crabs, measures to protect rock crabs are difficult to assess without an adequate understanding of the interactions between the 2 species. Therefore, the principal objective of this study was to determine the predation rates of rock crabs and green crabs in different laboratory experiments (competition treatments under different water temperatures and prey densities). We tested the hypothesis that the activity of rock crabs and green crabs differs in solitary, conspecific and heterospecific challenges. As the green crab is an aggressive competitor to other decapod species, we expected the predation rate of a rock crab to be lower in the presence of a green crab than in the presence of a conspecific, and that of a green crab not to be affected by competition. Expected responses may, however, vary with water temperature or prey availability. For instance, rock crabs are expected to outcompete green crabs in a cold environment while high prey abundance is expected to diminish competition between both species.

A set of field experiments was designed to complement results from the laboratory as well as to verify whether both crab species may feed on foulers found on mussels and aquaculture gear (mainly vase tunicates). Diving surveys were carried out to verify whether both crab species occur on the same mussel socks or are spatially segregated.

\section{MATERIALS AND METHODS}

Laboratory observations - predation rates. Animal collection: Laboratory experiments were conducted in autumn 2006 and repeated in spring 2007. One week before the experiments, divers collected adult male crabs in New London and St. Mary's bays (PEI, Canada). Only mature males were captured to avoid sex bias (Elner \& Hughes 1978, Miron et al. 2005). Carapace width $($ mean $\pm \mathrm{SD}$ ) was $63.11 \pm 7.60 \mathrm{~mm}$ for green and $92.31 \pm$ $13.16 \mathrm{~mm}$ for rock crabs. Crabs of each species were distributed into 3 holding tanks (at 5,12 and $20^{\circ} \mathrm{C}$, respectively; density 20 ind. $\mathrm{m}^{-2)}$, and acclimated for at least $7 \mathrm{~d}$. Tanks were $250 \mathrm{~cm}$ long x $100 \mathrm{~cm}$ wide $\times 48 \mathrm{~cm}$ high. The light:dark cycle was 10:14 h during autumn and 15.5:8.5 h during spring to simulate seasonal conditions. Blue mussels Mytilus edulis (10 to $35 \mathrm{~mm}$ length) were used as prey during the acclimation period and the experiments. Preliminary experiments in spring and summer 2006 had shown that crabs prefer this size-range and have no problem manipulating them. Mussels were collected at Lockhart Lake (New Brunswick, Canada), held at $18^{\circ} \mathrm{C}$ and a salinity of $26 \%$, and fed 'Live marine microalgae concentrate' (NutrOcean: Isochrysis galbana, Pavlova lutheri Nannochloropsis, $33 \%$ each). The stock of mussels was renewed every 2 wk. During acclimation, crabs were fed every day ad libidum.

Experimental enclosures and competition challenges. All challenges were carried out during daytime (9:00 to 17:00 h). As experimental enclosures, 8 aquaria $(50 \times 40 \times 40 \mathrm{~cm})$ were used, each with a sterilized $2 \mathrm{~cm}$ sand-gravel layer on the bottom and filled with artificial seawater (salinity: 26\%) from a closed-circuit filtering system. Water and sediments were replaced before each challenge. 
Crabs were studied using competition treatments: 1 solitary crab, 2 conspecifics, or 2 heterospecifics per experimental enclosure. Only crabs of similar size were used in experiments, average difference in carapace width was $6.4 \pm 8.7 \mathrm{~mm}$. Competition treatments were carried out at 3 temperatures $\left(5,12\right.$ or $20^{\circ} \mathrm{C}$ ) and 2 prey densities ( 4 or 30 mussels per aquarium). The temperatures used in challenges are observed off PEI between early May and early November (Audet et al. 2008). Prey densities were determined in preliminary experiments in spring and summer 2006. These experiments were carried out to determine a level of low prey density that would not impose any limitations on the number of prey eaten by each focal crab (hereafter referred to as predation rates). Our observations showed that crabs never ingested more than 4 mussels (e.g. solitary green crab at 5 and $12^{\circ} \mathrm{C}$ ) within the experimental time frame. When 2 individuals were placed in the same aquarium, crabs started to share the prey resource at densities between 5 and 10 mussels per aquarium. A density of 30 mussels per aquarium was chosen to saturate the bottom surface of the aquarium. A total of 288 challenges were carried out using a fully randomized and balanced design ( 2 species $\times 2$ seasons $\times 3$ competition treatments $\times 3$ temperatures $\times 2$ prey densities $\times 4$ replicates). Crabs were starved for $72 \mathrm{~h}$ prior to the challenges to stimulate feeding behaviour (e.g. Walton et al. 2002, Rossong et al. 2006). Before the start of the challenge, crabs were acclimated to their experimental enclosure for $15 \mathrm{~min}$. A black panel was used to isolate individuals during the $15 \mathrm{~min}$ acclimation period when 2 crabs were present in the same experimental enclosure. The challenge began once the mussels were randomly distributed on the bottom of the aquarium and crabs were acclimated. Challenges were recorded with a Sony CCDTRV 138 Hi8 Handycam for 4 consecutive hours (9:00 to 13:00 or 13:00 to 17:00 h). One crab was randomly chosen per challenge. An observer later viewed all challenges on the videotapes and scored the predation rate. Crabs were only used once.

Data analysis: Statistical analyses were performed with SAS 9.1. Predation rates were analyzed separately for each species for each season. Predation rates of green crabs during autumn were square root transformed and analyzed with a 2-way parametric analysis of covariance (ANCOVA). Predation rates for green crabs during springtime as well as predation rates for rock crabs for both seasons failed to meet the assumptions of the parametric ANCOVA. These predation rates were therefore analyzed with a 2-way nonparametric ANCOVA. Mussel densities and competition treatments were used as fixed factors and temperature as covariate for all analyses. The size difference between the competing crabs was included as a covariate in all the analyses in order to control its effects. This covariate was tested for interaction with other factors or covariate prior to its inclusion in the analyses and failed to interact with any factor or covariate. A power analysis was finally carried out with Power and Precision v.3 (Power and Precision 2007 Biostat. Accessed 2-6 Feb. www.power-analysis.com) to verify the smallest predation rate variation our experimental design could detect.

Field caging experiments - stomach contents. Experimental setup: A caging experiment was carried out twice in St. Mary's bay (PEI) in September 2007 to complement the laboratory experiment with 2 temporal replicates. Water temperature $\left(15\right.$ to $\left.17^{\circ} \mathrm{C}\right)$ and salinity $(30 \%$ ) remained relatively constant during the experimental period. Male crabs were captured by divers in the same area. Carapace width (mean \pm SD) measured $73.67 \pm 5.78 \mathrm{~mm}$ in green and $90.07 \pm$ $17.43 \mathrm{~mm}$ in rock crabs. Captured crabs were held in 2 cylindrical vexar ${ }^{\circledR}$ cages (length: $180 \mathrm{~cm}$; radius: $19 \mathrm{~cm}$; mesh size: $12 \mathrm{~mm}$; 1 cage per species, 35 crabs per cage) submerged near the experimental area and starved $24 \mathrm{~h}$ before the experiment. This starvation period was due to logistic constraints (in comparison to $72 \mathrm{~h}$ in the laboratory experiments).

Crabs were studied in competition treatments identical to the ones used in the laboratory experiment: 1 crab, 2 conspecifics or 2 heterospecifics. Competition treatments were randomly assigned to 1 of 6 cylindrical vexar ${ }^{\circledR}$ cages (length: $60 \mathrm{~cm}$; radius: $19 \mathrm{~cm}$; mesh size: $12 \mathrm{~mm}$ ) tied together on a line (60 cm apart). During each week of the experiment, 4 lines of 6 cages were deployed (4 replicates per week). Lines were laid perpendicular to a mussel longline approximately $20 \mathrm{~m}$ apart on the sea bottom in an aquaculture lease. Cages were left in the field for $7 \mathrm{~d}$. Each cage contained a $30 \mathrm{~cm}$ mussel sock section covered with fouling animals (mostly vase tunicates) hanging from the top of the cage. The typical mussel sock used by the aquaculture industry is a $3 \mathrm{~m}$ long mesh tube filled with farmed mussels that hangs on a long line. Average difference in carapace width between competing crabs was $7.9 \pm$ $9.6 \mathrm{~mm}$. One randomly selected focal crab from each cage was weighed at the beginning and end of the experiment. At the end of the experiment, these crabs were frozen $\left(-16^{\circ} \mathrm{C}\right)$ for stomach content analysis.

Prior to dissection, frozen crabs were thawed at ambient temperature for $4 \mathrm{~h}$. Stomachs were removed and weighed. Once opened, stomach fullness was visually estimated. Stomach content was rinsed into a Petri dish for identification and empty stomachs were weighed. The volume of each food item was estimated visually (adapted from Scarratt \& Lowe 1972 and Stehlik 1993). A total of 48 crabs was dissected.

Data analysis: The crab mass difference, mass of stomach content and \% of stomach fullness of each species were analyzed separately. A one-way parametric analysis of covariance (ANCOVA) was carried out on 
Table 1. Cancer irroratus and Carcinus maenas. 2-way ANCOVAs carried out on the predation rate of each crab species observed during autumn 2006. A non-parametric model was used for $C$. irroratus while square-root transformed rates were used for $C$. maenas. Size differential and temperature were used as covariates. The power levels determined from the power analysis to detect variations in the predation rates are shown. na: not applicable. Significant $p$-values are bold

\begin{tabular}{|llcccc|}
\hline \multirow{2}{*}{ Factors } & Crab species & $F$ & $\mathrm{df}$ & $\mathrm{p}$ & Power level \\
\hline Size differential & C. irroratus & 1.211 & 1 & 0.275 & na \\
& C. maenas & 0.23 & 1 & 0.632 & na \\
Temperature (T) & C. irroratus & 0.37 & 1 & 0.547 & 0.99 \\
& C. maenas & 8.58 & 1 & $\mathbf{0 . 0 0 4}$ & 0.99 \\
Competition (C) & C. irroratus & 0.01 & 2 & 0.989 & 0.52 \\
& C. maenas & 0.09 & 2 & 0.917 & 0.99 \\
Mussel density (D) & C. irroratus & 3.04 & 1 & 0.086 & 0.91 \\
& C. maenas & 0.00 & 1 & 0.984 & 0.99 \\
$\mathrm{~T} \times \mathrm{C}$ & C. irroratus & 0.67 & 2 & 0.518 & 0.73 \\
& C. maenas & 0.04 & 2 & 0.959 & 0.97 \\
$\mathrm{~T} \times \mathrm{D}$ & C. irroratus & 12.88 & 1 & $\mathbf{0 . 0 0 1}$ & 0.98 \\
& C. maenas & 1.50 & 1 & 0.225 & 0.99 \\
$\mathrm{D} \times \mathrm{C}$ & C. irroratus & 0.93 & 2 & 0.399 & 0.42 \\
$\mathrm{~T} \times \mathrm{D} \times \mathrm{C}$ & C. maenas & 0.01 & 2 & 0.990 & 0.99 \\
& C. irroratus & 1.85 & 2 & 0.166 & 0.65 \\
& C. maenas & 0.09 & 2 & 0.917 & 0.99 \\
\hline
\end{tabular}

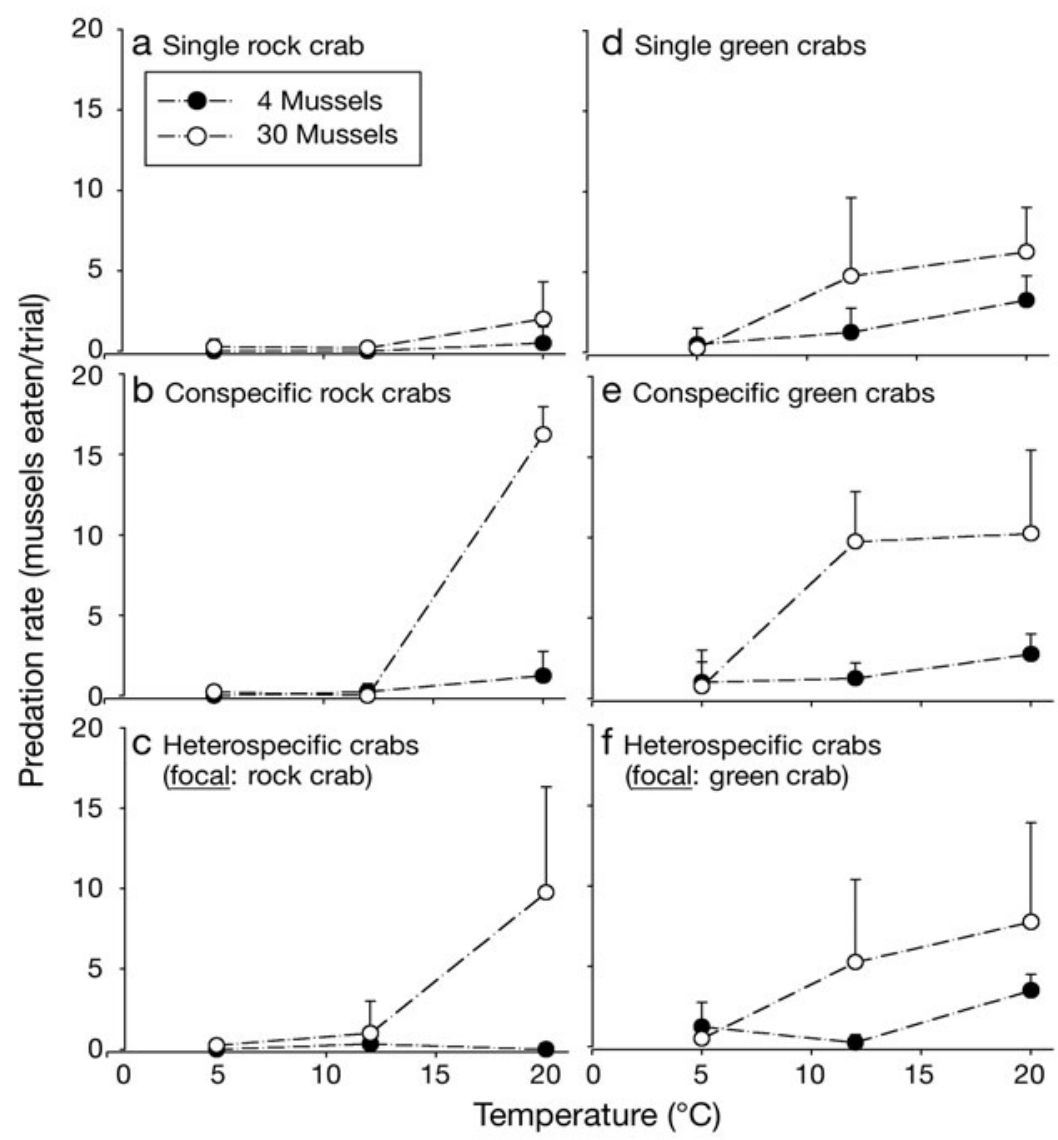

Fig. 1. Cancer irroratus and Carcinus maenas. Predation rate (mean $+\mathrm{SE})$ of each crab species observed during autumn 2006 in relation to competition treatments under various temperature and prey density conditions. Focal $=$ crab that is being observed
(1) \% stomach fullness, (2) log transformed mass difference and (3) mass of stomach content of rock crabs. A one-way parametric ANCOVA was also performed on the mass difference and the log transformed mass of stomach content of green crabs. The values for \% stomach fullness of green crabs did not meet the parametric assumptions of the ANCOVA and was analyzed with a one-way nonparametric ANCOVA. Competition treatment was used as a fixed factor in all analyses. The size difference between the competing crabs was included as a covariate in all analyses in order to control its effects. The covariate was tested for interaction with other factors or covariate prior to its inclusion in the analyses and failed to interact with any factor or covariate.

Diving surveys. Aquaculture leases usually contain parallel longlines, anchored at both ends and held near the surface with buoys. Up to 150 socks may hang down from a single longline. For a survey, a longline was randomly chosen, and divers assessed the abundance of the 2 crab species on 15 consecutive mussel socks to study their spatial distribution. Monthly surveys were carried out from June to October 2007 in various aquaculture leases at Brudenell point and at the mouth of the Cardinal River estuary (PEI), where both species are common. These areas were chosen due to logistic constraints; however, they are representative of the areas from which crabs were collected for the laboratory experiment. Diving survey results were analyzed qualitatively.

\section{RESULTS}

\section{Laboratory observations: predation rates}

\section{Autumn}

During autumn, rock crab predation rates varied significantly in relation to a Temperature $\times$ Mussel density interaction whereas green crab predation rates were significantly influenced only by temperature (Table 1). Predation rates of both species tended to increase wiith 
water temperature and mussel density (Fig. 1) though prey density did not affect significantly the green crab's predation rates (Table 1). The green crab started to show a clear feeding response at $12^{\circ} \mathrm{C}$ while it occurred at $20^{\circ} \mathrm{C}$ for rock crabs, particularly at the high mussel density (Fig. 1). Finally, predation rates of each species tended to be similar when facing a conspecific and a heterospecific (Fig. 1b,c,e,f).

\section{Spring}

In spring, and in contrast to autumn observations, the predation rates of rock crabs were significantly affected by a Temperature $\times$ Mussel density $\times$ Competition interaction (Table 2). Predation rates of rock crabs remained constant or increased under high temperature and high mussel density, but only in the presence of a competitor (Fig. 2b,c). Predation rates remained relatively constant in challenges using solitary rock crabs regardless of the temperature (Fig. 2a). Green crab predation rates increased significantly at the 2 higher temperatures (Table 2) similarly to what was observed during autumn (Fig. 2d,e,f). The predation rate of the green crab tended to be greater at high prey density (Fig. 2b,c,e,f), but not significantly (Table 2). Both species started clear foraging activities at $12^{\circ} \mathrm{C}$, except for solitary rock crabs (Fig. 2), and had similar predation rates in the presence of a conspecific or a heterospecific (Fig. 2b,c,e,f).

According to the power analysis carried out, our experimental design was strong enough to detect large- and medium-size effects. The probability to detect 40 and $25 \%$ variation in the observed predation rates was $>90 \%$ and 60 to $70 \%$, respectively. The probability dropped to $<20 \%$ to detect $10 \%$ variation (see right-hand side of Tables 1 and 2).

\section{Field caging experiments — stomach contents}

The majority of food items recovered in stomachs from both species was
Table 2. Cancer irroratus and Carcinus maenas. Results from 2-way nonparametric ANCOVAs carried out on the predation rate of each crab species observed during spring 2007. Size differential and temperature were used as covariates. The power levels determined from the power analysis to detect variations in the predation rates are shown. na: not applicable. Significant $p$-values are bold

\begin{tabular}{|llcccc|}
\hline \multirow{2}{*}{ Factors } & Crab species & $F$ & df & p & Power level \\
\hline Size differential & C. irroratus & 0.68 & 1 & 0.413 & na \\
& C. maenas & 0.33 & 1 & 0.568 & na \\
Temperature (T) & C. irroratus & 3.11 & 1 & 0.083 & 0.81 \\
& C. maenas & 8.77 & 1 & $\mathbf{0 . 0 0 4}$ & 0.99 \\
Competition (C) & C. irroratus & 0.09 & 2 & 0.918 & 0.09 \\
& C. maenas & 0.51 & 2 & 0.604 & 0.10 \\
Mussel density (D) & C. irroratus & 2.19 & 1 & 0.144 & 0.99 \\
& C. maenas & 0.09 & 1 & 0.760 & 0.99 \\
$\mathrm{~T} \times \mathrm{C}$ & C. irroratus & 0.48 & 2 & 0.623 & 0.56 \\
& C. maenas & 0.44 & 2 & 0.644 & 0.09 \\
$\mathrm{~T} \times \mathrm{D}$ & C. irroratus & 0.65 & 1 & 0.432 & 0.28 \\
& C. maenas & 2.24 & 1 & 0.140 & 0.80 \\
$\mathrm{D} \times \mathrm{C}$ & C. irroratus & 4.45 & 2 & $\mathbf{0 . 0 1 5}$ & 0.09 \\
$\mathrm{~T} \times \mathrm{D} \times \mathrm{C}$ & C. maenas & 0.54 & 2 & 0.585 & 0.27 \\
& C. irroratus & 3.89 & 2 & $\mathbf{0 . 0 2 5}$ & 0.60 \\
& C. maenas & 0.06 & 2 & 0.939 & 0.13 \\
\hline
\end{tabular}

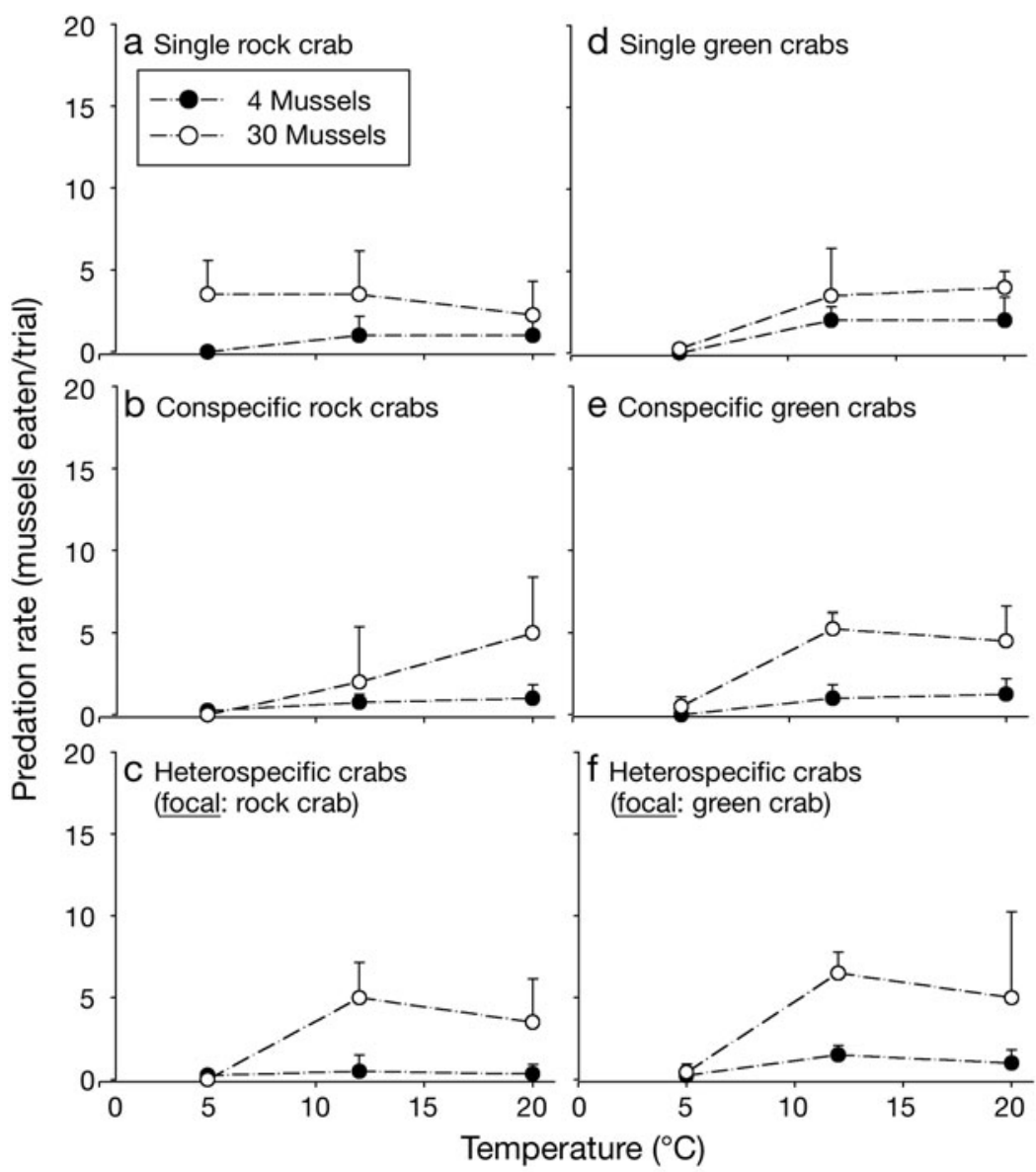

Fig. 2. Cancer irroratus and Carcinus maenas. Predation rate (mean $+\mathrm{SE}$ ) of each crab species observed during spring 2007 in relation to competition treatments under various temperature and prey density conditions. Focal $=\mathrm{crab}$ that is being observed 
Table 3. Cancer irroratus and Carcinus maenas. Crab mass difference, mass of stomach content and \% of stomach fullness of each crab species according to the competition treatment during the field caging experiments

\begin{tabular}{|lcrcc|}
\hline $\begin{array}{l}\text { Competition } \\
\text { treatment }\end{array}$ & $\begin{array}{c}\text { Crab } \\
\text { species }\end{array}$ & $\begin{array}{c}\text { Crab mass } \\
\text { difference }(\mathrm{g})\end{array}$ & $\begin{array}{c}\text { Mass of stomach } \\
\text { content }(\mathrm{g})\end{array}$ & $\begin{array}{c}\text { \% of stomach } \\
\text { fullness }\end{array}$ \\
\hline Single & C. irroratus & $-2.12 \pm 3.43$ & $0.48 \pm 0.08$ & $28 \pm 40$ \\
& C. maenas & $0.85 \pm 0.66$ & $0.09 \pm 0.07$ & $7 \pm 8$ \\
Conspecifics & C. irroratus & $0.08 \pm 1.27$ & $0.13 \pm 0.08$ & $17 \pm 26$ \\
& C. maenas & $1.40 \pm 0.76$ & $0.19 \pm 0.14$ & $15 \pm 31$ \\
Heterospecifics & C. irroratus & $1.06 \pm 1.06$ & $0.16 \pm 0.28$ & $26 \pm 34$ \\
& C. maenas & $1.65 \pm 1.20$ & $0.34 \pm 0.52$ & $33 \pm 44$ \\
\hline
\end{tabular}

blue mussel debris (e.g. shell, byssal threads). Less than $20 \%$ of all stomachs contained traces of vegetation and bryozoans. Vase tunicates (debris) were observed in neither species. Crab mass difference, variability in stomach content mass and \% of stomach fullness were highly variable in both crab species regardless of the competition treatment (Table 3). The competition treatments and the size difference between competing crabs did not influence significantly the crab mass difference, mass of stomach content or \% of stomach fullness of either species.

\section{Diving surveys}

Crab abundance on mussel lines was generally low (Fig. 3). Only rock crabs were observed on mussel socks in June (Fig. 3) while green crabs were almost

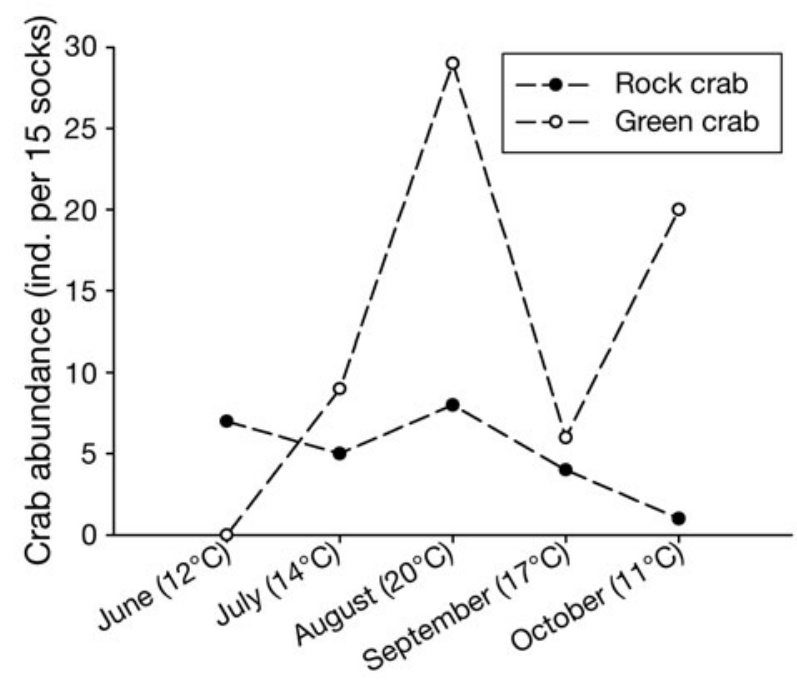

Fig. 3. Cancer irroratus and Carcinus maenas. Abundance of each crab species on mussel socks during the diving surveys. The abundance of each crab species was summed from all 15 mussel lines observed during each survey exclusively observed in October (Fig. 3). Both crab species were found on the mussel socks during the other surveys (Fig. 3). Rock crabs and green crabs were never observed on the same mussel sock except for the August survey where 3 mussel socks were shared by both species. During that particular survey, rock crabs that shared a mussel sock with green crabs were observed on the top section of the sock closer to the water surface. Green crabs were observed near the bottom of the mussel lines. Green crab abundance tended to increase with increasing water temperatures from June to August and was lower in September and October with decreasing water temperatures. Rock crab abundance remained stable from June to August and decreased in September and October (Fig. 3).

\section{DISCUSSION}

\section{Laboratory observations - predation rates}

The predation rates of both species increased at a high temperature $\left(20^{\circ} \mathrm{C}\right)$ throughout the challenges regardless of the season. High temperature is known to accelerate most physiological processes, including enzymatic reactions regulating the metabolism. Faster digestion will occur, and the need to ingest food will increase. In this study, the warm temperature may have stimulated crabs to forage, and thus increased their predation rate. This is consistent with other studies carried out on the rock crab (e.g. Barbeau \& Scheibling 1994) as well as on the green crab (e.g. Wallace 1973).

Both crab species, however, responded differently to temperature. In this study, increased foraging activity by rock crabs at $20^{\circ} \mathrm{C}$ occurred only during the autumn laboratory challenges. Rock crabs may have been adapted to the warm temperature occurring in PEI waters during the autumn $\left(17^{\circ} \mathrm{C}\right)$ at the time of their capture. This may have contributed to their low predation rates observed at the 2 lowest temperatures during the autumn challenges. The thermal tolerance of crabs varies with seasons. Crabs are adapted to the temperature of the ongoing season even when an acclimation period of 7 to $21 \mathrm{~d}$ is given (Cuculescu et al. 1998, Hopkin et al. 2006). Inversely, rock crabs were foraging at $5^{\circ} \mathrm{C}$ during spring laboratory challenges, mostly when an individual was alone in the experimental enclosure, and showed clear feeding activities at $12^{\circ} \mathrm{C}$. Rock crabs were at that time captured in cold PEI waters $\left(6^{\circ} \mathrm{C}\right)$. 
This is consistent with observations made by Stehlik et al. (2004) in Virginia, New York and New Jersey (USA). The general activity of rock crabs and their population abundance decreases during spring as water temperature warms up $\left(10^{\circ} \mathrm{C}\right)$ and increases in winter when water temperature drops to $6-7^{\circ} \mathrm{C}$. The cold water observed in PEI during spring would be more favorable to the general behaviour of rock crabs.

Green crabs clearly showed foraging activities at $12^{\circ} \mathrm{C}$ which were almost inexistent at $5^{\circ} \mathrm{C}$, regardless of the studied season. Cold temperatures are reported to be a limiting factor for green crabs and may, for instance, inhibit feeding $\left(7^{\circ} \mathrm{C}\right)$ (Ropes 1968) and molting (Audet et al. 2003) as well as kill their eggs and thus limit their geographical progression (Audet et al. 2003). In contrast to rock crabs, temperature at the time of their capture did not influence their predation rates.

The predation rates of both species were generally greater at high mussel density, although not always significantly. Similar results were observed in studies using cancrid (Boulding \& Hay 1984), portunid (Kuhlmann \& Hines 2005) and xanthid crabs (Silliman et al. 2004). High prey density may stimulate crabs to forage more intensively because they are chemosensory and tactile predators (Elner \& Hughes 1978). As mussel density increases, concentration of chemical cues increases as well as the probability to encounter a prey. Visual perception may also have contributed to stimulate the crabs since the experiment was conducted in daylight.

Overall, the green crab did not appear to impede the predation success of the rock crab. The predation rates of both species were similar either in the presence of a conspecific or a heterospecific regardless of the season. Due to a low number of replicates $(n=4)$, our experimental design might not have been powerful enough to discriminate between small variations in the predation rates. Similar results, however, were observed while studying the time budget of these crabs in similar experimental conditions (Bélair \& Miron unpubl.). These data combined to the ones presented in this study suggest that green crabs and rock crabs could coexist in natural conditions.

\section{Field caging experiment - stomach contents}

Complete digestion is variable among crab species. For instance, the digestive system of blue crabs may be completely emptied after 18 h (McGaw \& Reiber 2000) whereas it may take as long as 48 to $49 \mathrm{~h}$ in green crabs and graceful crabs Cancer gracilis (Hopkin \& Nott 1980, McGaw 2005). However, stomach retention time for food during the digestion process seems similar in cancrid and portunid crabs: $<12 \mathrm{~h}$ in green crabs (Hopkin \& Nott 1980), 9 h in graceful crabs (McGaw 2005), and 8 to $10 \mathrm{~h}$ in blue crabs (McGaw \& Reiber 2000). Food items from the stomachs are thus representative of the last 8 to $12 \mathrm{~h}$ crabs spent in their cage.

Mussel debris represented the main food item recovered in crab stomachs. Bivalve debris is commonly found in rock crab (Scarratt \& Lowe 1972) and green crab stomachs (Ropes 1968). Our results did not indicate vase tunicate consumption by crabs though Carver et al. (2003) documented that rock and green crabs may eat tunicates, which, however, was the only food source in the latter study. Video observations also showed that rock crabs may tear off and/or dislodge tunicates from mussel socks (Marc Ouellette, Department of Fisheries and Oceans, pers. comm.). Rock crabs may possibly remove foulers without eating them to gain access to mussel prey. Tunicates may be digested more rapidly than other food items, explaining their absence in crab stomachs. Green crabs have been reported by some authors to be ineffective in controlling foulers (e.g. Ross et al. 2004). Our results support this. In PEI, green crabs were often hiding within clumps of vase tunicates covering the mussel socks and appeared to use them as a shelter (M. Ouellette, Department of Fisheries and Oceans, pers. comm.).

Overall, our competition treatments did not influence the stomach contents of either crab species. Crab mass difference and mass of stomach content were variable throughout the challenges. The results of the caging experiment tend to support a potential coexistence between both species as mentioned earlier. This may, however, not apply to all life stages. MacDonald et al. (2007) showed that green crab juveniles are a potential threat to juvenile blue crabs, though adult blue crabs are known to limit the expansion of green crabs on the east coast of the United States (MacDonald et al. 2007).

\section{Diving surveys}

Our diving surveys suggest that both crab species avoided each. Both species displayed different abundance patterns during the monthly surveys. As already observed in European (Naylor 1962) and PEI waters (Audet et al. 2008), the green crab abundance in our study increased (June to August) and then decreased (September and October) with water temperature. The green crab abundance, however, was very low in the September survey, probably related to aquaculture husbandry practices. Shellfish farmers in St. Mary's bay clean their mussel lines during that period to remove tunicates, also removing crabs during the process. The rock crab abundance remained low through- 
out our surveys during the warm summer months but should increase during winter when water temperature drops (D. Audet \& G. Miron unpubl. data). Rock and green crabs were rarely found on the same mussel sock, and when they were, different sections of the mussel sock were exploited by each species.

The passive and active avoidance of the $2 \mathrm{crab}$ species may reduce interspecific competition and enable them to coexist. Spatial and temporal segregation have been shown to allow coexistence in other crab species. For instance, blue crabs, lady crabs Ovalipes ocellatus and rock crabs seem to have a strong spatial overlap in the Hudson-Raritan Estuary (USA) (Stehlik et al. 2004). However, the 3 crab species display a temporal segregation pattern, which presumably decreases competition. When rock crabs migrate in the estuary in December, lady crabs migrate out while blue crabs bury themselves and become inactive. Chilean intertidal predatory crabs show spatial segregation which presumably decreases competition as well (Navarrete \& Castilla 1990). Adults of Acanthocyclus gayi are usually found in rock crevices while $A$. hassleri are found in mussel beds.

\section{CONCLUSIONS}

Our hypothesis that predation rates and mass of stomach content of the rock crab would be lower in the presence of a green crab rather than a conspecific was not supported by our results. Predation rates and stomach contents of the rock crab, as well as the green crab, remained unaffected by the presence of a heterospecific. During the diving surveys, individuals of different species were observed to avoid each other passively (temporal segregation) and actively (spatial segregation). Our results suggest that rock and green crab adults may coexist due to a segregation in time and space. Predation by rock or green crabs on fouling animals could not be confirmed. Mussel farmers may not benefit from the presence of rock crabs on mussel lines as much as they expect.

The extrapolation of our results to a larger context should be done with caution. The predation rates were studied under controlled conditions in small experimental enclosures and our experimental design might have failed to detect small predation rate variations. Furthermore, the stomach contents were studied in field caging experiments at small temporal and spatial scales. Video observations from field experiments and annual monitoring programs are clearly needed to validate our results and to underline the mechanisms that allow a potential coexistence between the rock crab and the green crab. A higher number of replicates may also reveal subtle but important behavioural changes.
Acknowledgements. We thank S. Landry, K. Burke, M.J. Abgrall, C. Mills, D. MacKinnon and S. Haché for their help in the field and in the laboratory. Special thanks are addressed to M. Ouellette (Department of Fisheries and Oceans) and his team (J.F. Mallet, A. LeBlanc, J. Hill, R. Sonier, D. Bourque, M. Hardy and L. Comeau) for the field work (logistic and experimental design) and B. Gillis (Department of Fisheries and Aquaculture of PEI) for making the diving surveys possible. We also thank G. Moreau and R. Rochette for their assistance in the project. S. Reebs and M.A. Villard kindly provided various field and laboratory equipment. R. Fournier (NutrOcean ) provided phytoplankton concentrates. Finally, we thank D. Wilbur who gave us access to Lockhart Lake to collect mussels. The constructive comments from all anonymous reviewers greatly improved the manuscript. Funding for this research has been provided by grants from the Department of Fisheries and Oceans, Canadian Foundation for Innovation and Université de Moncton to G.M. The Université de Moncton and Patrimoine canadien provided scholarships to M.C.B.

\section{LITERATURE CITED}

Audet D, Davis DS, Miron G, Moriyasu M, Benhalima K, Campbell D (2003) Geographical expansion of a nonindigenous crab, Carcinus maenas (L.), along the Nova Scotian shore into the southeastern Gulf of St. Lawrence, Canada. J Shellfish Res 22:255-262

> Audet D, Miron G, Moriyasu M (2008) Biological characteristics of a newly established green crab (Carcinus maenas) population in the southern gulf of St. Lawrence, Canada. J Shellfish Res 27:427-441

Barbeau MA, Scheibling RE (1994) Temperature effects on predation of juvenile sea scallops (Placopecten magellanicus [Gmelin]) by sea stars (Asterias vulgaris Verrill) and crabs (Cancer irroratus Say). J Exp Mar Biol Ecol 182:27-47

Beukema JJ (1991) The abundance of shore crab Carcinus maenas (L.) on a tidal flat in the Wadden Sea after cold and mild winters. J Exp Mar Biol Ecol 153:97-113

Boulding EG, Hay TK (1984) Crab response to prey density can result in density-dependant mortality of clam. Can J Fish Aquat Sci 41:521-525

Carver CE, Chisholm A, Mallet A (2003) Strategies to mitigate the impact of Ciona intestinalis (L.) biofouling on shellfish production. J Shellfish Res 22:621-631

Cuculescu M, Hyde D, Bowler K (1998) Thermal tolerance of two species of marine crab, Cancer pagarus, and Carcinus maenas. J Therm Biol 23:107-110

Elner RW, Hughes RN (1978) Energy maximization in the diet of the shore crab, Carcinus maenas. J Anim Ecol 47: $103-116$

Floyd T, Williams J (2004) Impact of green crab (Carcinus maenas L.) predation on a population of soft-shell clams (Mya arenaria L.) in the southern Gulf of St. Lawrence. J Shellfish Res 23:457-462

Glude JB (1955) The effects of temperature and predators on the abundance of the softshell clam Mya arenaria in New England. Trans Am Fish Soc 84:13-26

Grosholz E, Ruiz GM (1996) Predicting the impact of the introduced marine species: lessons from the multiple invasions of the European green crab Carcinus maenas. Biol Conserv 78:59-66

Grosholz E, Ruiz GM, Dean CA, Shirley KA (2000) The impacts of a non-indigenous marine predator in a California bay. Ecology 81:1206-1224

> Hidu H, Conory C, Chapman SR (1981) Suspended culture of oysters: biological fouling control. Aquaculture 22:189-192 
Hopkin SP, Nott JA (1980) Studies on the digestive cycle of the shore crab Carcinus maenas (L.) with a special reference to the B cells in the hepatopancreas. J Mar Biol Assoc UK 60:891-907

Hopkin RS, Qari S, Bowler K, Hyde D, Cuculescu M (2006) Seasonal thermal tolerance in marine Crustacea. J Exp Mar Biol Ecol 331:74-81

Kuhlmann ML, Hines AH (2005) Density-dependant predation by blue crabs Callinectes sapidus on natural prey populations of infaunal bivalves. Mar Ecol Prog Ser 295: 215-228

Leonard GH, Ewanchuk PJ, Bertness MD (1999) How recruitment, intraspecific interactions, and predation control species borders in a tidal estuary. Oecologia 118:492-502

Lodeiros CJ, Himmelman JH (2000) Identification of environmental factors affecting growth and survival of the tropical scallop Euvola (Pecten) ziczac in suspended culture in Golfo de Cariaco, Venezuela. Aquaculture 182:91-114

MacDonald JA, Roudez R, Glover T, Weis JS (2007) The invasive green crab and Japanese shore crab: behavioural interactions with a native crab species, the blue crab. Biol Invasions 9:837-848

McDonald PS, Jensen GC, Armstrong DA (2001) The competitive and predatory impacts of the nonindigenous crab Carcinus maenas (L.) on early benthic phase Dungeness crab Cancer magister Dana. J Exp Mar Biol Ecol 258:39-54

McGaw IJ (2006) Feeding and digestion in low salinity in an osmoconforming crab, Cancer gracilis, II. Gastric evacuation and motility. J Exp Biol 209:3777-3785

McGaw IJ, Reiber CL (2000) Integrated physiological responses to feeding in the blue crab Callinectes sapidus. J Exp Biol 203:359-368

Miron G, Audet D, Landry T, Moriyasu M (2005) Predation potential of the invasive green crab (Carcinus maenas) and other common predators on commercial bivalve species found on Prince Edward Island. J Shellfish Res 24: $579-586$

> Navarrete SA, Castilla JC (1990) Resource partitioning between intertidal predatory crabs: interference and refuge utilization. J Exp Mar Biol Ecol 143:101-129

> Naylor E (1962) Seasonal changes in a population of Carcinus

Editorial responsibility: Matthias Seaman, Oldendorf/Luhe, Germany maenas (L.) in the littoral zone. J Anim Ecol 31:601-609 Ropes RW (1968) The feeding habits of the green crab, Carcinus maenas (L.). Fish Bull (Wash DC) 67:183-203

> Ross KA, Thorpe JP, Brand AR (2004) Biological control of fouling in suspended scallop cultivation. Aquaculture 229: 99-116

Rossong MA, Williams J, Comeau M, Mitchell SC, Apaloo J (2006) Agonistic interactions between invasive green crabs, Carcinus maenas (Linnaeus), and juvenile American lobsters, Homarus americanus (Milne Edwards). J Exp Mar Biol Ecol 281:281-288

Scarratt DJ, Lowe R (1972) Biology of rock crab (Cancer irroratus) in the Nothumberland Strait. J Fish Res Board Can 29:161-166

Silliman BR, Layman CA, Geyer K, Zieman JC (2004) Predation by the black-clawed mud crab, Panopeus herbstii, in Mid-Atlantic salt marshes: further evidence for top-down control of marsh grass production. Estuaries 27:188-196

Stehlik LL (1993) Diets of the brachyuran crabs Cancer irroratus, C. borealis and Ovalipes ocellatus in the New York bight. J Crustac Biol 13:723-735

Stehlik LL, Pikanowski RA, McMillan DG (2004) The HudsonRaritan estuary as crossroads for distribution of blue (Callinectes sapidus), lady (Ovalipes ocellatus), and Atlantic rock (Cancer irroratus) crabs. Fish Bull (Wash DC) 102: 693-710

- Vernberg FJ, Vernberg WB (1970) Lethal limits and the zoogeography of the faunal assemblages of coastal Carolina waters. Mar Biol 6:26-32

Wallace JC (1973) Feeding, starvation and metabolic rate in the shore crab, Carcinus maenas. Mar Biol 20:277-281

Walton WC, Makinnon C, Rodriguez LF, Protor C, Ruiz GM (2002) Effect of an invasive crab upon a marine fishery: green crab, Carcinus maenas, predation upon a venerid clam, Katelysia scalarina, in Tasmania (Australia). J Exp Mar Biol Ecol 272:171-189

- Williams J, Floyd T, Rossong MA (2006) Agonistic interactions between invasive green crabs, Carcinus maenas (Linnaeus), and sub-adult American Lobsters, Homarus americanus (Milne Edwards). J Exp Mar Biol Ecol 329: $66-74$

Submitted: August 11, 2008; Accepted: April 30, 2009 Proofs received from author(s): June 15, 2009 